purposefully balanced on age, district, educational attainment, employment status, and income. Eight FGs were conducted; participants were stratified by sex and sexual behaviour in the past 12 months.

Results Yong adults who were abstinent said they were making this choice because they treasured virginity; and wanted to stay STD-free and avoid pregnancies. There were drawbacks, particularly for women who said that their boyfriends may leave if they did not have sex. Peer pressure and feeling excluded from those who were having sex were also disadvantages.

Ugandan young adults talked about the cultural norm of having multiple partners, both for financial gain and social status. Using condoms was universally noted as the right thing to do. At the same time, sexually active youth voiced several barriers to condom use, including: being allergic to rubber, fear of getting cancer with frequent use, and embarrassment. When asked about how confident they were in negotiating condoms, sexually experienced women voiced a range or responses from 'I can't at all' to 'sometimes' to 'always'.Refusing sex was possible: If a woman did not want to have sex, respondents said she could blame it on her period and if a man did not want to have sex, he could say he was 'tired'. That said, all agreed that the refusal of sex in a relationship could be met with consequences (e.g., distrust by one's partner, an end to the relationship).

Conclusion Several important challenges that Uganda young adults faces in making healthy sexual decisions were voiced. These issues need to be directly addressed in HIV prevention programs tailored to this age group.

\section{P4.67 STI TESTING BEHAVIOUR AMONG SEXUAL MINORITY ADOLESCENT WOMEN RECRUITED FROM FB IN THE UNITED STATES}

${ }^{1}$ Michele Ybarra, ${ }^{1}$ Tonya Prescott, ${ }^{1}$ Myeshia Price-Feeney, ${ }^{2}$ Elizabeth Saewyc, ${ }^{3}$ Margaret Rosario. ${ }^{1}$ Centre for Innovative Public Health Research, San Clemente, USA; ${ }^{2}$ University of British Columbia, Vancouver, USA; ${ }^{3}$ City University of New York, New York City, USA

\subsection{6/sextrans-2017-053264.563}

Introduction Despite what adolescent health practitioners may assume, multiple studies have found that lesbian, gay, and bisexual (LGB) girls are more likely than heterosexual girls to have unprotected penile-vaginal sex, engage in penile-anal sex, have multiple sexual partners, have high risk sexual partners, and to get pregnant. In the face of these disparities, it is unknown if LGB girls are getting tested for STIs.

Methods Ninety-one 14-18 year old cisgender females who identified as sexual minority (i.e., had a sexual identity other than exclusively heterosexual) and lived in the United States were recruited through Facebook and surveyed online in July 2016.

Results Twenty-nine percent of respondents estimated they lived in a lower than average income household. Seventy-five percent were White race; $11 \%$ were Hispanic ethnicity. Two in five respondents (42\%) lived in a suburban area, one in four (27\%) lived in an urban area, and just under one in three $(30 \%)$ lived in a small town or rural area.LGB girls reported rates of lifetime STI testing (21\%) similar to rates of HIV testing (19\%). Four percent said they had ever tested positive for an STI; none reported a positive HIV test.Compared to $6 \%$ of LGB girls who have only had sex with girls,
$30 \%$ of LGB girls who have only had sex with guys, and $46 \%$ of girls who have had sex with guys and girls have ever been tested for an STI $(p=0.01)$.Although not statistically significant, LGB girls who did not use a condom at last penilevaginal sex $(62 \%)$ were more likely than those who did $(35 \%)$ to have ever been tested for STIs $(p=0.15)$.

Conclusion It may be that LGB girls who have male partners, either exclusively or while also having female partners, are aware of the STI risk that penile-vaginal sex may confer and are testing accordingly. The higher rates of STI testing in the face of lower condom use however, may suggest that some LGB teens who are having sex with guys are using testing instead of condoms as a form of STI prevention.

\section{P4.68 INTERNALISED OF HIV-RELATED STIGMA AND ASSOCIATED FACTORS AMONG HIV-INFECTED ADULTS RECEIVING CARE}

${ }^{1}$ Mina Qobadi, ${ }^{1}$ Ali Dehghanifirouzabadi, ${ }^{2}$ Tiffany Mcdonald, ${ }^{1}$ Tametria Samms, ${ }^{1}$ Kendra Johnson. ${ }^{1}$ Mississippi State Department of Health, Jackson, USA; ${ }^{2}$ Mississippi State Department of Health, Jacskon, USA

\subsection{6/sextrans-2017-053264.564}

Introduction Internalisation of HIV-related stigma may affect a person's disease management and his her accessibility to services. However, little is known about HIV-related stigma and its associated factors in patients with HIV. We aimed to examine HIV-related stigma and its associated factors.

Methods We used Mississippi Medical Monitoring Project (MMP) data from 2011 to $2014(\mathrm{n}=793)$. MMP is a crosssectional surveillance system designed to assess the behavioural and clinical characteristics of HIV-infected adults at least 18 years of age receiving outpatient care in the United States. Dependent variable was HIV-related stigma. Our independent variables were gender, sexual orientation, race, age, education, poverty level, smoking, binge drinking, drug abuse, length of time diagnosed with HIV, and insurance. T-test, one-way ANOVA, and multiple linear regression were conducted $(\mathrm{p}<0.05)$.

Results Overall, 75\% of respondents reported at least one internalised HIV-related stigma experience. The average stigma score overall was 2.3 (out of 6), with a standard error of 0.07. Our finding showed that stigma was significantly higher among females $(\mathrm{M}=2.6, \mathrm{t}=2.9, \mathrm{p}=0.003)$, patients aged 18$24(\mathrm{M}=2.9, \mathrm{~F}=4.6, \mathrm{p}=0.003)$, those with less than high school education $(\mathrm{M}=2.7, \mathrm{t}=2.4, \mathrm{p}=0.02)$, binge drinker $(\mathrm{M}=2.8, \quad \mathrm{t}=2.3, \quad \mathrm{p}=0.02)$, drug abuser $(\mathrm{M}=2.7, \mathrm{t}=2.3$, $\mathrm{p}=0.02$ ), those who have been diagnosed with HIV since $<5$ years ago $(\mathrm{M}=2.6, \mathrm{~F}=6.6, \mathrm{p}=0.001)$, and those who had private insurance $(\mathrm{M}=2.8, \mathrm{~F}=5.5, \mathrm{p}=0.004)$. Multiple linear regression analysis showed that being female $(\beta=0.52)$, having less than high school education $(\beta=0.55)$, drug abusing $(\beta=0.66)$, and having private insurance $(\beta=0.77)$ contribute positively to predict experiencing stigma after entering all variables together.

Conclusion The findings indicate that HIV-related stigma is very common among HIV patients, and is significantly associated with gender, education, drug abuse and insurance status, highlighting a need for stigma reduction interventions, with a focus on population at risk. 